\title{
Balkanologie
}

Balkanologie Revue d'études pluridisciplinaires

Vol. X, $n^{\circ} 1-2 \mid 2008$

Volume $X$ Numéro 1-2

\section{Une histoire arménienne des guerres balkaniques}

\author{
Anahide Ter Minassian
}

\section{OpenEdition}

Journals

Édition électronique

URL : http://journals.openedition.org/balkanologie/364

DOI : 10.4000/balkanologie.364

ISSN : 1965-0582

\section{Éditeur}

Association française d'études sur les Balkans (Afebalk)

\section{Référence électronique}

Anahide Ter Minassian, « Une histoire arménienne des guerres balkaniques », Balkanologie [En ligne], Vol. X, n 1-2 | 2008, mis en ligne le 23 novembre 2011, consulté le 17 décembre 2020. URL : http:// journals.openedition.org/balkanologie/364; DOI : https://doi.org/10.4000/balkanologie.364

Ce document a été généré automatiquement le 17 décembre 2020.

(c) Tous droits réservés 


\title{
Une histoire arménienne des guerres balkaniques
}

\author{
Anahide Ter Minassian
}

\section{Des guerres balkaniques à la question arménienne : le parcours d'Aram Andonian}

1 Aram Andonian (1875-1951), né à Constantinople, mort à Paris, est l'auteur ou plus exactement le «réalisateur $»^{1}$ - un terme qui rend compte de la scénographie mise en oeuvre - de cet ouvrage, une entreprise industrielle, nécessairement collective, compte tenu de son ampleur, du coût de production et des délais rapides de fabrication. Lancée en novembre 1912, la publication est en effet achevée en août 1913. Aram Andonian a été un journaliste polémiste et ambitieux. Collaborateur ou fondateur de journaux arméniens plus ou moins éphémères, il a été un dessinateur, caricaturiste féroce de la presse satirique arménienne stambouliote entre 1909 et $1915^{2}$. Aram Andonian a eu du talent, une plume facile et une conception personnelle du journalisme, un journalisme d'investigation et de combat - précurseur du "quatrième pouvoir" - révélateur de sa psychologie et de ses aspirations.

2 Curieusement, on dispose de peu d'éléments biographiques sur celui qui fut aussi à Paris, de 1928 jusqu'à son dernier jour, le 23 décembre 1951, le premier bibliothécaire de la Bibliothèque Nubar ${ }^{3}$, devenue au cours des ans une institution fréquentée par les «arménologues» du monde entier. Du long article nécrologique que lui consacra le quotidien parisien Haratch ${ }^{4}$, il ressort que sa vie et ses activités à Bolis ${ }^{5}$ avant 1914 sont mal connues et ont toujours intrigué ses contemporains. En 1911, son nom apparaît parmi les députés de l'Assemblée nationale arménienne ${ }^{6}$ de Constantinople comme représentant d'un quartier de la capitale. Pour répondre à la demande de Teodig (1873-1928), le directeur d'un célèbre almanach populaire arménien ${ }^{7}$, il brosse, sur le mode de l'autodérision les grandes lignes de son "autobiographie". Ses origines sont modestes. Né à Péra, fils d'un pécheur arménien ou d'un employé dans une pêcherie d'Etat, appelé Andon, il passe sa petite enfance à Scütare où un maître arménien lui 
inculque rudement des rudiments de lecture et d'écriture, puis il fréquente de 8 à 12 ans l'école arménienne Narekian de Péra et enfin, à Koule Kapou, le collège St. Pierre des "Frères français" qu'il quitte avant ses 14 ans. C'est le parcours classique d'un intellectuel ottoman autodidacte et encyclopédique qui dit avoir tout appris par luimême. Si il a probablement pratiqué, en fonction des circonstances, le détournement autobiographique, Aram Andonian a acquis la réputation justifiée de maîtriser l'arménien, le français, le turc et d'être un collectionneur de livres et un bibliophile passionné. Adolescent sans ressources, ayant tôt déserté le foyer familial, il survit en faisant tous les métiers et commence à écrire et à dessiner. Les encouragements qu'il reçoit d'écrivains reconnus à Constantinople, tels Hrand Assadour et Krikor Zohrab ${ }^{8}$, à la suite de quelques brèves publiées dans le quotidien Arevelk (Orient $)^{9}$ déterminent sa vocation de journaliste arménien et son entrée dans une carrière aussi semée d'embûches que dépouillée de lustre. Il se fait connaître comme «l'enfant terrible des rédactions arméniennes » où l'on apprécie sa capacité de savoir «boucler » un article, où il apparaît toujours élégamment vêtu, une canne à la main et coiffé d'un fès planté de biais. Une allure de dandy oriental masquant son impécuniosité permanente.

Ses vingt ans coïncidèrent avec les massacres arméniens de 1894-1896 dont les derniers épisodes firent dans les rues de Constantinople (27-28 août 1896), des milliers de victimes parmi les hamal et poussèrent à l'exil des intellectuels arméniens. Il gardera toute sa vie la haine d'Abdülhamid II et de son régime despotique -le zouloum- entre 1878 et 1908. Durant ces décennies, il n'existait pas de partis politiques chez les Arméniens de Constantinople, mais des «tendances » qui s'exprimaient, sous le couvert de questions littéraires ou religieuses, dans une presse, sévèrement contrôlée par la censure. Un exercice dans lequel Aram Andonian excella. Doté d'une plume acérée et "plus pamphlétaire que critique», il se fit remarquer par ses haines et ses parti pris, la passion le conduisant souvent à la partialité ${ }^{10}$. Capable de générosité autant que de malignité, il passait pour être incontrôlable. 
TU.S4toPU.9u.

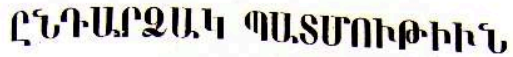 TULPULEUL TUSEPU.2Uh}

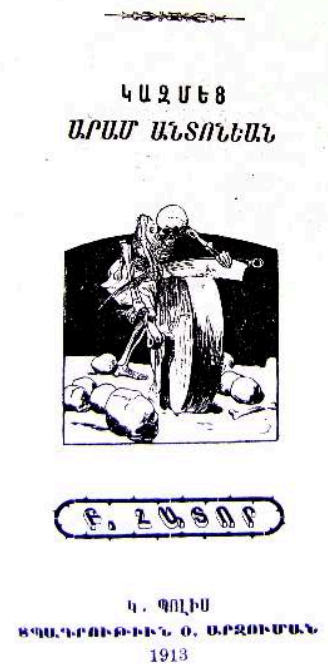

4 Après la révolution jeune-turque de juillet 1908, la restauration de la Constitution de 1876 et la proclamation de la liberté, il se dit verakazmial-hintchakian ${ }^{11}$ et lance ses foudres contre les adversaires ou les concurrents de son parti, en particulier contre le Dachnaktzoutioun ou Fédération Révolutionnaire Arménienne ${ }^{12}$. Lecteur vorace, esprit observateur et curieux, travailleur infatigable, il donne libre cours à sa passion pour la langue et la littérature arméniennes et contribue à faire connaître des écrivains arméniens provinciaux, Telkadetzi (1860-1915), Rouben Zartarian (1874-1915), Hovhannes Kazandjian, Ardaches Haroutounian (1873-1915). Entré dans l'intimité de Krikor Zohrab et de Gabriel Noradounghian, il a probablement adhéré comme eux à la franc-maçonnerie ce qui lui permet d'entrer dans des cercles turcs. De 1911 à 1913, il se met au service de Zohrab dont il édite les nouvelles ${ }^{13}$, se lance dans l'étude des conflits balkaniques et utilise l'arme politique de la caricature dans la presse satirique ${ }^{14}$, avant d'être embauché, dès l'entrée de la Turquie en guerre (novembre 1914), dans le service de censure ottomane à Constantinople comme lecteur de la correspondance arménienne. Une fonction qui lui permet de découvrir les exactions dont sont déjà victimes les communautés arméniennes micrasiates et d'alerter, au début de l'année 1915, le patriarche Zaven.

5 Le 24 avril 1915, il fait partie des quelques centaines d'intellectuels arméniens de Constantinople arrêtés et déportés en Anatolie pour y être exécutés. A la suite de circonstances quasi- miraculeuses, il échappe au sort de la majorité et se retrouve à Alep où il participe, à la fin de la guerre, au recensement des Arméniens survivants sortis des déserts de Syrie et de Mésopotamie et prend la mesure de l'ampleur du désastre ${ }^{15}$. Son livre Ayn sev oreroun (En ces jours noirs) publié à Boston, en 1919, un recueil de six récits, est un témoignage sur le sort tragique des déportés arméniens en 1915-1916. 
Entre 1919 et 1920, durant la Conférence de la Paix, il dirige à Paris l'organe éphémère de l'Union nationale arménienne libérale, Hayastan (Arménie) et publie tour à tour, Les massacres d'Alep, Rapport d'un témoin oculaire (Paris, 1919), Documents officiels concernant les massacres arméniens, Reproduction photographique d'un grand nombre de documents (Paris, 1920). The memoirs of Naim bey, Turkish officials documents relating to the deportations and massacres of Armenians with an introduction by Viscount Gladstone, (London, 1920, édition arménienne, Boston 1921), est un livre dans lequel un fonctionnaire turc, Naïm bey, révèle les télégrammes du ministre de l'Intérieur de l'Empire ottoman, Talaat pacha, ordonnant la déportation et l'extermination des Arméniens. Un livre qui fait date, qui engage une vive polémique historique et reste contesté par les historiens turcs ${ }^{16}$. Son poste de bibliothécaire à Paris, obtenu grâce à la protection de Gabriel Noradounghian, va permettre à Aram Andonian, littéralement retranché dans sa bibliothèque, de constituer à partir de 1928 un fonds, les Matériaux pour l'histoire du génocide arménien, amplement reproduits et cités par l'actuel bibliothécaire de la Bibliothèque Nubar, Raymond Kévorkian ${ }^{17}$.

7 Pour mesurer l'intérêt de l'ouvrage d'Andonian, La guerre balkanique, un exposé assez détaillé des opérations militaires entre 1912 et 1913 s'impose d'autant que la concertation entre les coalisés s'est rarement traduite sur le terrain par un regroupement des forces et par des batailles menées en commun.

8 Au moment où l'empire ottoman sort affaibli d'une guerre avec l'Italie qui a envahi la Tripolitaine (septembre 1911), puis occupé les îles du Dodécanèse, au moment où l'Albanie est en révolte contre Istanbul et l'armée turque en pleine réforme, la Russie qui a subi, face aux Japonais, une sévère défaite militaire en Extrême-Orient (1904-1905) et, face aux Autrichiens, une défaite diplomatique (1909) entend jouer un rôle plus actif dans les Balkans ${ }^{18}$. Elle favorise l'union des petits Etats balkaniques désireux de se partager les dépouilles de l'Empire ottoman. Signé à l'initiative de la Russie, l'accord du 7 mars 1912 prévoit une coopération militaire entre Bulgares et Serbes contre Vienne et Istanbul et la partition de la Macédoine et des régions voisines sous arbitrage russe. Quelques mois après, la Grèce humiliée par son échec crétois (1909) est intégrée, avec le Monténégro, à la Ligue balkanique (septembre 1912). 
Illustration 2 - carte illustrée montrant la répartition de la population et des forces armées des Etats engagés dans la guerre balkanique.

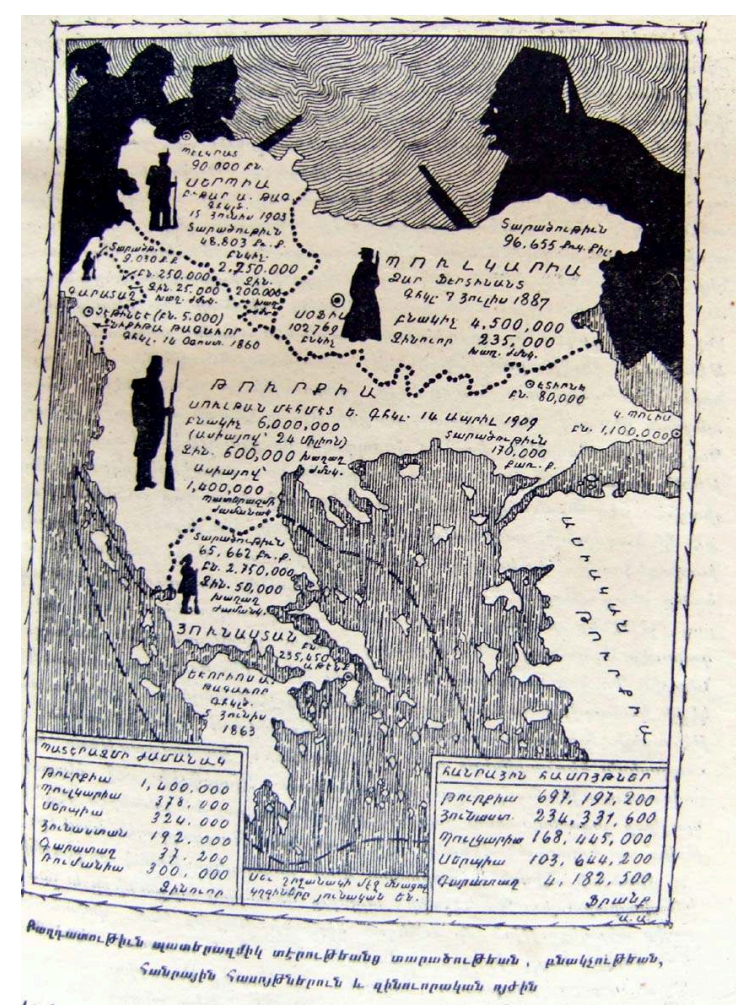

9 Les guerres balkaniques ont passionné l'opinion publique, ont suscité immédiatement une abondante littérature avant d'être reléguées au second plan par la Première guerre mondiale. La résurgence en 1991 des anciens problèmes et des nouvelles questions (disparition de l'URSS, effondrement de la Yougoslavie, statut de la Bosnie, statut de la Macédoine, statut du Kosovo, frontières du nouvel Etat serbe, etc.) ont réveillé l'intérêt des historiens pour ce premier conflit européen du XXe siècle, prolégomènes des deuX guerres mondiales - la « Guerre de Trente ans »- de 1914 à $1945^{19}$.

\section{La Première guerre balkanique (18 octobre-3 décembre 1912 et 3 février-30 mai 1913)}

Elle s'ouvre à la suite d'une montée des tensions entre les membres de la Ligue balkanique et la Turquie. En quelques jours, la guerre, une guerre de mouvement menée indépendamment par chacun des coalisés tourne au désastre pour les Ottomans.

Le Monténégro devance ses alliés en se jetant ( 9 octobre) avec une petite armée de soldats rustiques, patriotes et endurants sur la ville de Scütari où les Turcs ne cèdent pas. Les offensives, bulgare en Thrace et serbe en Macédoine, connaissent des succès spectaculaires. Les Bulgares, dotés d'artillerie et de mitrailleuses avancent le long des vallées du Vardar et de la Maritza. D'une part ils assiègent Edirne, d'autre part ils emportent, après de violents combats, Kirkilissé (22octobre), Lulé Burgas (31 octobre) où se déroulent les scènes d'enfer d'une armée ottomane et d'un peuple musulman en déroute.

"Mêlées à la tourbe des soldats, des milliers de charrettes à boeufs où les habitants $\mathrm{du}$ pays ont rassemblé tous leurs biens, s'en vont vers Stamboul. C'est l'émigration de tout un peuple, le retour du Turc vers l'Asie"20. 

l'état de siège et dont le ministre des Affaires étrangères est Gabriel effendi Noradounghian, un Arménien très modéré. Mais les défaites turques, attribuées à l'incapacité du Ministre de la Guerre, le général Nâzim Pacha, relancent la popularité du Comité Union et Progrès au sein de l'armée. La rumeur selon laquelle le Grand Vizir Kiamil Pacha veut signer au plus vite la paix et céder Edirne aux Bulgares, précipite les événements. Le 23 janvier 1913, Enver et Talaat beys à la tête d'une bande de 200 Jeunes-Turcs font irruption dans les bâtiments de la Sublime Porte où siège le Conseil des Ministres. Nâzim Pacha et son aide de camp sont tués à bout portant, les autres ministres s'enfuient, le Grand vizir Kiamil Pacha est contraint à démissionner. Le même jour, le général Mahmoud Chevket Pacha qui avait contribué à la déposition d'Abulhamid II lui succède. Les Jeunes-Turcs sont désormais au pouvoir : ils le resteront jusqu'au 30 octobre 1918. Le «triumvirat» des unionistes, Talaat, Enver, Djémal, instaure un régime de répression, dénonce l'armistice et relance les hostilités dans les Balkans. Mais, après cinq mois de siège, les Bulgares qui ont reçu le renfort de l'artillerie serbe viennent à bout de la résistance turque à Edirne (26 mars 1913). Un mois après, les Monténégrins entrent enfin à Scütari (23 avril 1913). Le traité de paix signé à Londres sous l'égide des Puissances (30 mai 1913) laisse aux Turcs, Istanbul et la 
zone limitrophe des Détroits. Toutes les autres possessions européennes ottomanes sont partagées entre les membres de la Ligue balkanique. La Crète a été attribuée à la Grèce qui conserve Salonique. Les Etats balkaniques sont prêts à s'affronter pour le partage de la Macédoine et de l'Albanie.

\section{La Deuxième guerre balkanique (30 juin 1913-10 août 1913)}

16 Elle est déclenchée par les Bulgares qui ont le sentiment d'avoir fourni, en mobilisant l'armée la plus nombreuse l'essentiel de l'effort de guerre et d'avoir été évincés du partage de la Macédoine par les Grecs et les Serbes. D'abord pleine d'élan, l'attaque bulgare (30 juin) est bloquée par la contre-offensive serbe et grecque. La Roumanie intervient soudainement dans le conflit. Elle déclare la guerre à la Bulgarie et sans rencontrer de résistance occupe la Dobroudja méridionale (11 juillet 1913) et menace Sofia. Profitant du désarroi des Bulgares, les Turcs les attaquent à leur tour (22 juillet) : menés par Enver, ils enlèvent et occupent Edirne. Après l'échec d'une attaque contre les Grecs sur le Strouma, la Bulgarie demande l'armistice (31 juillet). La guerre n'a duré qu'un mois, mais elle a été particulièrement sauvage. Les "atrocités " bulgares, grecques et turques qui ont eu un retentissement international, suscitent dès l'été 1913 l'enquête de la Commission Carnegie ${ }^{22}$. La Paix de Bucarest (10 août 1913) entérine la défaite de la Bulgarie qui ne reçoit que des miettes en Macédoine et en Thrace occidentale et l'échec de la diplomatie russe. La Grèce conserve Janina - un avant-poste face à l'Albanie devenue indépendante - la Macédoine méridionale avec Salonique et Kavalla ; la Serbie garde la Macédoine septentrionale et le Kosovo ; la Roumanie obtient la Dobroudja ; la Turquie récupère la Thrace orientale avec Edirne.

Ultime épisode ou presque de la Question d'Orient, les guerres balkaniques ont inspiré une abondante littérature de témoins, de reporters et d'observateurs militaires au cours de la succession accélérée des événements. Ces guerres ont permis aux Grandes Puissances divisées en «blocs», Triple Entente et Triple Alliance, d'intervenir par la voie diplomatique dans un conflit qui a bouleversé l'équilibre régional établi à Berlin en 1878. Elles ont permis de vérifier l'excellence de leurs armes (canons Krupp ou Schneider-Creusot, mitrailleuses, shrapnels, fusils Mauser ou Mannlicher, cartouches de dynamite etc.) ainsi que le bien-fondé de leur tactique, de leur doctrine militaire (offensive à la française ? défensive enseignée par von der Goltz à l'armée ottomane ?) et de leur formation logistique (communications, système sanitaire). Car tous les combattants, petits Etats balkaniques et Empire ottoman, ont été armés et équipés précédemment par la France, l'Allemagne, la Russie, l'Autriche-Hongrie et l'Italie. Tous ont instauré un service militaire obligatoire y compris l'empire ottoman où la conscription a été étendue aux non musulmans en 1909 et tous ont procédé à des mobilisations nationales. En 1912, au début de la guerre, les Bulgares ont mobilisé 350000 hommes, les Grecs 110000 , le Monténégro, 35 600, les Serbes, $230000^{23}$. Les chiffres de l'armée ottomane dispersée dans un empire immense, immobilisée dans le Yémen ou en Anatolie ne sont pas connus et il existe d'immenses différences entre les troupes bien entraînées du Nizam et celles du Rédif (Réserve). Dans toutes les armées, l'infanterie est formée de paysans souvent illettrés mais fortement endoctrinés par une idéologie nationaliste et/ou religieuse. 


\section{La guerre balkanique d'Aram Andonian : le choc des photos au service d'une histoire immédiate}

18 que les épisodes de la Première guerre balkanique, d'octobre 1912 au printemps 1913 :
la publication s'est arrêtée alors que la guerre est finie mais la paix n'est pas encore conclue. Publiée « à chaud », c'est un bon exemple « d'histoire immédiate » utilisant la forme et les méthodes des magazines européens de l'époque - un texte agrémenté de photographies, d'images, de cartes, de commentaires - destinée à satisfaire les exigences d'information et à flatter le goût du sensationnel du public populaire arménien. Ambitieuse fresque entraînant le lecteur dans les arcanes de la géopolitique des Balkans et d'une épopée militaire "moderne », le livre donne l'impression qu'une armée de reporters s'est portée sur tous les fronts et dans tous les camps.

En fait, Aram Andonian n'a jamais quitté Constantinople et n'a aucune expérience des champs de bataille et des scènes qu'il décrit. Et bien que Léon Trotsky se soit déplacé de Belgrade à Sofia, de Bucarest dans la Dobroudja pour mener, au plus près du théâtre des opérations, son enquête sur les guerres balkaniques ${ }^{24}$, le cas d'Andonian n'est pas unique. En fait, dans cette guerre courte, les informations ont été fournies aux intéressés par des officiers francophones de chaque camp. Les sources d'Andonian sont exclusivement françaises ${ }^{25}$. Il a lu et interprété les ouvrages, livres et articles, des historiens, des journalistes et des militaires français. Ces derniers sont venus constater sur les fronts bulgare et serbe ${ }^{26}$, le bien fondé de la doctrine militaire élaborée par l'Etat-Major français : des offensives massives de fantassins dont la route est ouverte par l'artillerie de campagne à tir rapide ${ }^{27}$. Il a utilisé leurs cartes et leurs clichés. Cela suppose qu'il a disposé de collaborateurs, capables de traduire vite, la publication du livre ayant commencé en novembre 1912, un mois après le début des hostilités. Et aussi de cartographes, capables de dresser des cartes de géographie historique qu'il s'agisse de Byzance et des phases successives de l'évolution de l'Empire ottoman, des principautés médiévales et des revendications territoriales de chaque peuple balkanique. Ou alors de collaborateurs capables de reproduire (à moins qu'Andonian ne l'ait fait lui-même) des cartes de géographie politique (démographie et forces en présence des belligérants, p. 389), de géographie humaine (Monténégro et Kosovo, p. 99), d'opérations militaires (itinéraires des armées, voies ferrées et vallées fluviales), siège d'Edirne,( p. 81), bataille de Tchataldja, (p. 1026), marche hellène sur Salonique, ( p. 110), marche bulgare sur Edirne, (p. 753), marche bulgare sur Salonique, (p. 840), panoramiques de la bataille de Schkodra, (p. 572-573), de Monastir, ( p. 757-758), de Salonique, (p. 844-845), etc. en y portant la toponymie et les légendes en caractères arméniens finement dessinés à l'encre de Chine. Une belle performance !

Divisé en cinq parties, la Question d'Orient (pp.7-422), la guerre de la Turquie (pp. 422-542), du Monténégro ${ }^{28}$ (pp. 549-684), de la Serbie ( pp. 685-780), de la Grèce (pp.781-907), de la Bulgarie pp.908-1032), l'ouvrage s'ouvre par une préface ${ }^{29}$ qui établit un terrible constat: la Turquie a cessé d'être un Etat européen! La Ligue balkanique, coalition improbable de petits Etats chrétiens décidés à bouter la Turquie hors d'Europe, a réussi cet exploit sans l'intervention des Puissances. La guerre a donné la preuve de la faiblesse militaire de l'Empire ottoman, imputable au régime hamidien comme à l'imprévoyance des Jeunes-Turcs ${ }^{30}$. 
21 Pour aider le lecteur à comprendre les causes des guerres balkaniques et leurs enjeux, Andonian entreprend d'exposer la Question d'Orient du Congrès de Berlin (1878) à la Révolution de juillet 1908. Le récit détaillé qu'il fait de ce qui fut l'une des questions capitales de la politique européenne et le cauchemar de générations de lycéens est puisé dans l'ouvrage classique d'Edouard Driault et dans les travaux de René Pinon et de Victor Bérard ${ }^{31}$. Andonian ne leur emprunte pas seulement des données, mais il épouse la méfiance et les inquiétudes des Français face à la pénétration économique allemande dans l'Empire ottoman avec la construction de la Bagdad Bahn. Il dénonce le rapprochement entre Abdulhamid II et Guillaume II et n'hésite pas à imputer la responsabilité des défaites turques à la mission militaire allemande de von der Goltz qui s'est montrée incapable de moderniser l'armée ottomane.

Sur un fond de mosaïque ethnique et religieuse, d'insurrections, de massacres et de conflits interétatiques, il dresse, un tableau des aspirations opposées des peuples et des Etats balkaniques, de l'affaiblissement et du recul, depuis 1878, de l'empire ottoman en Europe et en Asie Mineure, de la politique d'intervention des Puissances dans l'imbroglio régional (Macédoine, Albanie, Bosnie-Herzégovine, Crète, Chypre).

Écrit par un Arménien et destiné à des Arméniens, c'est d'abord un réquisitoire contre Abdulhamid II accusé d'avoir instauré un régime de bureaucratie policière, d'avoir pratiqué une politique d'oppression et de massacres, d'avoir, bien que dépendant financièrement de l'Europe, constamment recherché, et réussi, à échapper aux promesses de réformes administratives, sous la garantie des Puissances, auxquelles il s'était engagé à Berlin. Mais c'est aussi un réquisitoire contre la diplomatie prédatrice de ces mêmes Puissances "protectrices des chrétiens", à la recherche de sphères d'influence, de marchés, de débouchés maritimes, dont les rivalités, éclatantes jusque dans le réseau des dynasties balkaniques, sont depuis l'entrevue de Reval (1908) formalisées par la Triple Entente et la Triple Alliance. Bien informé, rédigé avec talent, clair et vivant, le récit d'Andonian fourmille d'éléments où ne manquent ni les chants des tchétés monténégrins, ni les télégrammes des généraux ottomans, ni les commentaires du journal Tanin proche des Jeunes-Turcs.

Car, Aram Andonian a aussi observé durant la guerre la vie politique à Constantinople, la lutte entre l'Ittihad et l'Ittilaf, l'ancrage rapide des Jeunes-Turcs dans le nationalisme turc. Extrêmement critique à l'égard de ces derniers, il dénonce leur despotisme, un despotisme pire que celui du sultan qu'ils ont renversé. La Révolution de Juillet 1908, malgré la restauration de la Constitution ne mérite pas son nom : elle n'a pas eu pour objectif d'établir la liberté mais de sauver l'empire. Et Andonian de prévenir! L'incapacité du gouvernement ottoman de réaliser les réformes a conduit à la perte de la Turquie d'Europe. "Si cette situation se prolonge en Turquie d'Asie, il est impossible que la suite soit différente, car, ici aussi, sont réunies toutes les conditions qui ont conduit à la perte de la Turquie d'Europe : des conflits ethniques, la question agraire, une administration désastreuse, des privilégiés et des exploiteurs et la rivalité des Puissances ${ }^{32}$. L'audace de ses propos surprend. Mais, lorsqu'il commence la publication de son Histoire de la guerre balkanique, les libéraux ottomans sont au pouvoir et les Jeunes-Turcs persécutés.

Pour rédiger son histoire Andonian a utilisé uniquement des sources françaises ou traduites en français ${ }^{33}$. Parmi les ouvrages qu'il a consultés, celui auquel il accorde la palme est dû à Alain de Pennenrun sur la campagne de Thrace ${ }^{34}$. Toutefois une lecture attentive montre que c'est le livre du lieutenant-colonel Boucabeille ${ }^{35}$ auteur d'une lumineuse synthèse, malgré «le véritable puzzle auquel il a fallu se livrer pour tenter de 
retrouver quelques parcelles de vérité dans le chaos des contradictions et d'imprécisions qu'une presse, trop abondamment informée peut-être, a publié sur la matière $»^{36}$ qui a le plus inspiré Andonian. Ce dernier lui a emprunté le plan, la méthode ( rendre compte de certains faits à travers une certaine mentalité et d'un point donné de l'espace ») et les conclusions de son propre ouvrage ${ }^{37}$.

Mais, emporté par son imagination, par une sensibilité orientale et populiste, Andonian a rédigé au courant de la plume un véritable roman historique, peuplé de personnages hauts en couleur, émaillé de commentaires politiques désabusés et teinté d'humour noir. Malgré ses allusions répétées à l'héroïsme des soldats et des généraux turcs, malgré son apparente affliction devant les défaites ottomanes et les menaces qui pèsent sur l'empire, Andonian cache à peine son admiration pour le vaillant petit peuple de la "Montagne noire", ces "primitifs de la révolte" que sont les Monténégrins, sa sympathie pour les Bulgares, et sa conviction qu'il existe une homothétie entre la Macédoine et l'Arménie ${ }^{38}$.

Comme l'annonce le titre de l'ouvrage, cette Histoire de la guerre balkanique, est une histoire «illustrée " et il ne fait aucun doute que les illustrations contribuent à renforcer l'intérêt du livre. Dessinateur et caricaturiste, Andonian est un visuel. Il a saisi la force des images, ce qu'on appellera plus tard le « choc des photos ». Ces images, photographies, dessins, gravures, cartes iconiques, oeuvres de reporters photographes ou d'artistes inconnus ont valeur de documents. Leur succession, leur invention scénique précipitent le lecteur au coeur des événements. Les images disent souvent plus que le texte.

Dans les 400 premières pages du livre dédiées à la Question d'Orient, il existe un décalage constant entre les images et le texte, à l'exception des gravures représentant les signataires des traités de San Stéfano et de Berlin en 1878 (pp. 26-27). Cette licence permet à l'éditeur de présenter les souverains des Etats en guerre. Le premier portrait, en pleine page (p. 8), est celui de Mehmet Rechad V le sultan-calife ottoman dont l'allure débonnaire et pacifique sous les ors de l'habit impérial contraste avec celle des souverains balkaniques caricaturés en guerriers burlesques (p.12). Mais les photographies suivantes corrigent cette image, montrent ces souverains sur les champs de bataille. Ils y apparaissent en chefs de guerre conformément à la représentation médiévale du pouvoir royal. La présence insistante du prince héritier semble affirmer une continuité dynastique soumise aux risques de coup d'Etat ou d'attentat ${ }^{39}$. Nicolas de Monténégro, souverain d'un micro-Etat de 300000 habitants, est celui qui joue le mieux ce rôle. Il se montre en cavalier à la tête d'une escouade d'officiers ou de vieux tchétés qui ont rempilé. Son fils, un géant, le Prince Danilo s'affiche en soldat. Ferdinand de Saxe-Cobourg, « czar » de Bulgarie, souverain de l'Etat dont l'armée est la plus moderne et son fils, le Prince Boris, se font photographier auprès d'une locomotive ou d'une pièce d'artillerie durant le siège de Tchataltcha. Ni le roi Georges, ni le prince héritier Constantin de Grèce, ni le roi Bétar de Serbie ne dérogent à la règle. Un montage photographique associant les quatre souverains de la coalition accentue cette personnalisation des nations en guerre (p.88). Au contraire, l'image du sultan est rare et les portraits des généraux et pachas turcs (Abdullah, Hussein Hilmi, Nazem, Feri, Zeki, Ahmed Tevfik etc. ) ou du Cheikh-ul-islam l'emportent par le nombre sur ceux des princes impériaux ottomans. Les généraux bulgares (Fizen, Vazov, Rozov, Safov, Dimitreev, Dikov etc.), eux, sont pléthores et l'Etat-Major bulgare à Stara-Zagora (p. 
245-246) donne l'image d'un corps d'officiers impeccables, portant bottes rutilantes, vestes à épaulettes et décorations.

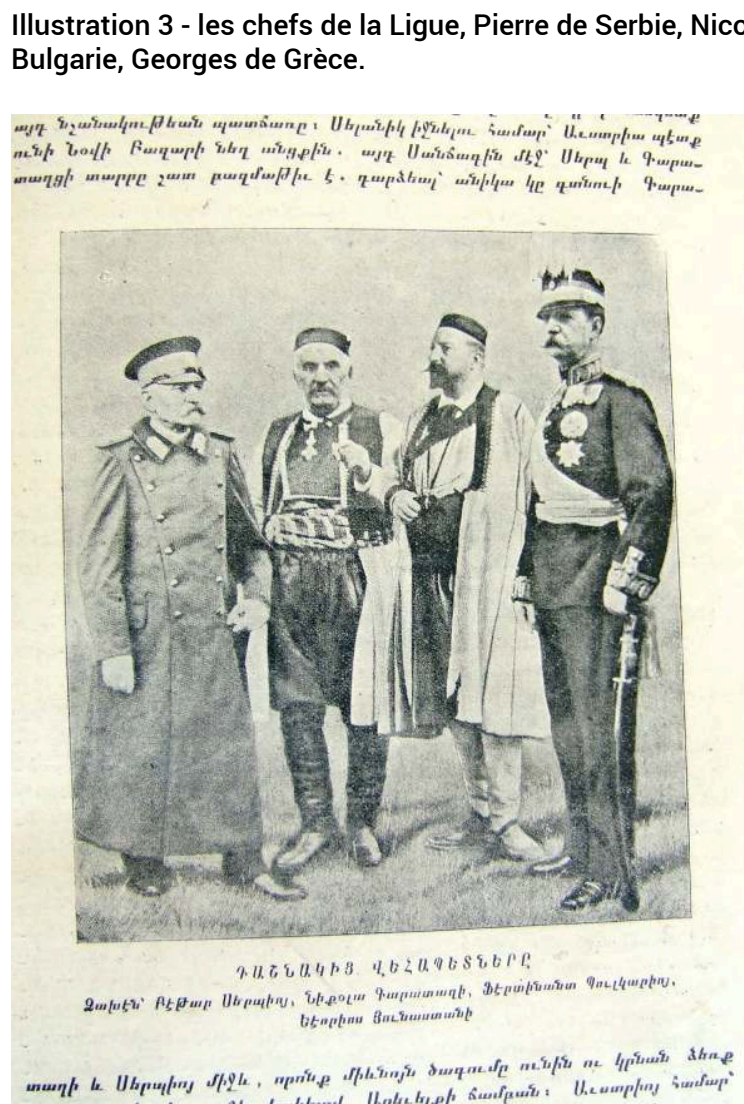

La mobilisation des hommes est un thème qui a inspiré partout les photographes. Il n'est pas étonnant que l'on ait accordé une place importante à la mobilisation dans l'empire ottoman dans un ouvrage publié à Constantinople. Les photos sont révélatrices de la diversité, de la modernisation inachevée et des archaïsmes de l'empire. Qu'il s'agisse du départ des réservistes arabes en habits traditionnels entassés dans des wagons de marchandise à Damas (p. 91), des troupes "asiatiques" embarquées dans une barque (p.116), des soldats transportés dans une barge primitive ( p. 486), de la parade somptueuse de la cavalerie ottomane devant le Ministère de la Guerre ( p.117), du départ, devant ce même Ministère, du premier contingent de mobilisés entouré d'une foule masculine dont les coiffes (turbans, fez, papakhs ) révèlent les identités ethniques ou sociales (p. 121), du tohu-bohu d'hommes, de chevaux et de charrettes dans les rues de Constantinople (supplément pp.508-509), des pièces du service télégraphique de l'armée ottomane entassées dans un chariot traîné par de buffles (p. 508), et, encore et toujours, des cohortes d'hommes résignés marchant vers les champs de bataille européens. La guerre a réveillé les passions nationalistes - à Istanbul, la foule hurle harb! harb! ( guerre! guerre!) (p. 439), les étudiants manifestent aussi en faveur de la guerre( p. 456) - et a accentué les divisions politiques comme le montrent les énormes meetings tenus séparément par les Ittihadistes ( p. 432) et les Ittilafistes (p. 438) sur la place Sultan Ahmed.

Les images des mobilisations bulgare, serbe et grecque traduisent le même enthousiasme populaire des premiers jours de la guerre, amplifié par les bénédictions des prêtres. Avec cependant une différence notable : à Sofia, à Belgrade, à Athènes : des 
femmes et des enfants se mêlent aux manifestants. Chez les Serbes - magnifique image de propagande- des femmes, en robe et tablier, s'entraînent au maniement du fusil (p. 149), mais «Mademoiselle Sofia Ivanovitch» porte un uniforme de soldat (p. 72) et des garçons à peine adolescents s'engagent comme combattants. Dans un groupe de tchétés grecs, on remarque la présence d'une femme (p. 779); la blonde chevelure d'une superbe « volontaire hellène » s'étale entre son fusil, ses cartouchières et sa croix (p. 784). Quant aux Monténégrins, ils donnent l'image d'un peuple qui en toute circonstance fait corps avec son roi (p. 32). Les femmes, de robustes femelles, s'attellent aux fûts des canons, des paysans âgés et déguenillés se portent volontaires (p.87). Même à Istanbul, signe des changements en cours, les femmes et les enfants apportent publiquement leur soutien à l'effort de guerre: dans le Grand Bazar des musulmanes voilées promènent leurs petits garçons habillés en soldats.(p. 417).

Illustration 4 - les enfants serbes saluent l'héroïne nationale serbe, Sophia Ivanovic et son fiancé.

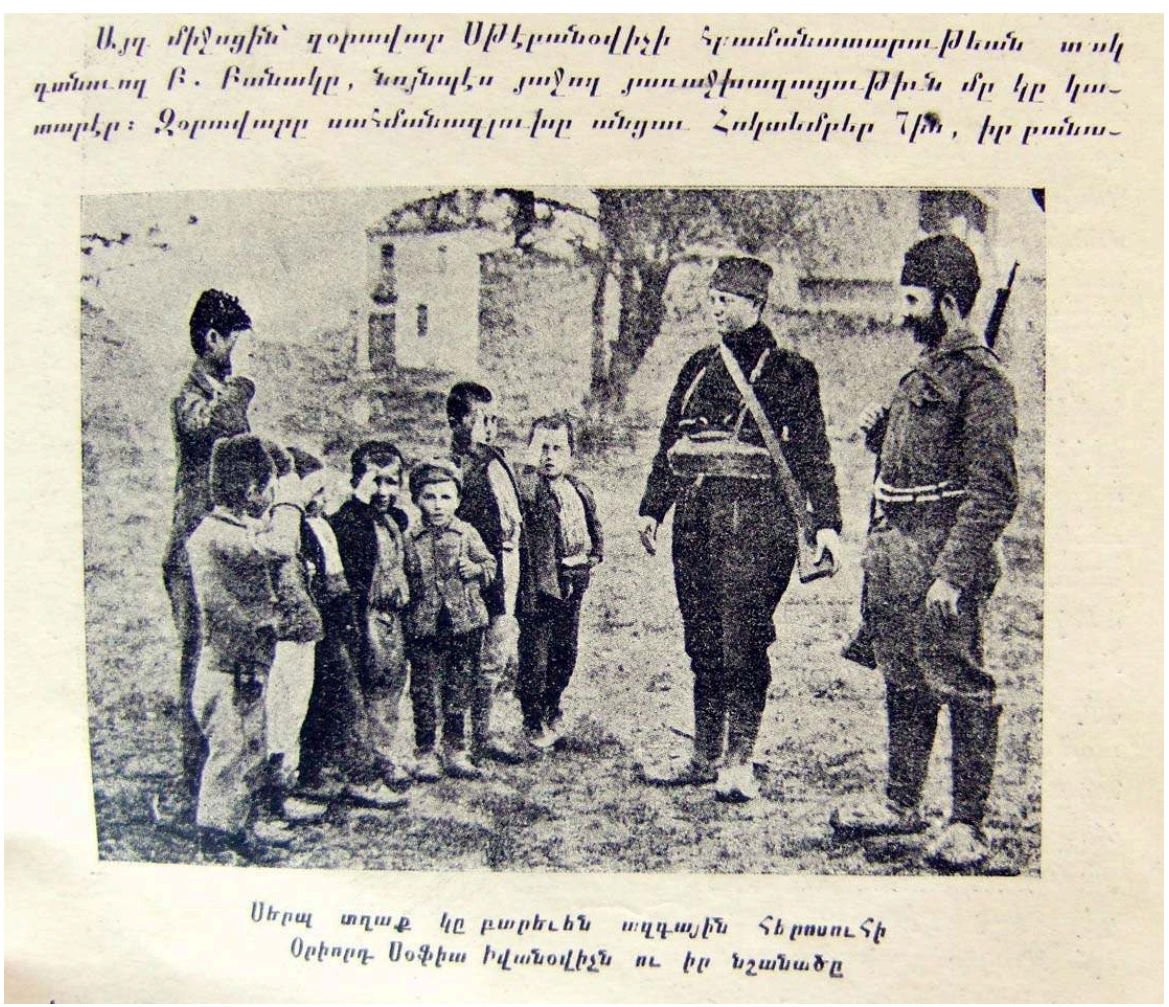

31 Les photographies donnent une représentation visuelle de "l'esprit d'offensive" qui anime les armées serbe et bulgare. Ainsi, on voit des fantassins bulgares étendus et collés au sol (p.153). Chaque fantassin-tirailleur est muni d'un fusil et d'une pellebêche. Le champ de bataille est jalonné de légères excavations individuelles creusées par le tirailleur lui-même au cours de son mouvement par bonds (que l'on devine), sous le couvert de l'artillerie à tir rapide installée sur une hauteur. On retrouve la même scène et le même usage de la bêche - qui deviendra l'outil du fantassin en 1914 ! - chez les Serbes dans la bataille de Koumanovo ( p. 278). Des hommes, sans casque, bravent le feu de l'ennemi et gagnent du terrain en creusant des trous protecteurs. L'intensité du feu est suggérée par des vues de tranchées où les soldats sont terrés : donnant un exemple de courage, des soldats turcs jouent aux cartes sous les tirs d'obus dans un abri improvisé. Elle l'est aussi par une photo de combat de nuit durant laquelle l'armée bulgare identifie la position de ses adversaires turcs grâce à un puissant projecteur (p. 
153). Partout l'artillerie est présente: Bulgares, Serbes, Grecs ont été dotés par la France, les Monténégrins par la Russie, les Turcs par l'Allemagne ${ }^{40}$. Le transport des pièces d'artillerie par des chemins bourbeux rendus impraticables par les incessantes pluies d'automne exige des chevaux, des soldats, des civils, y compris des femmes, des efforts surhumains (p. 169, p. 302).

Illustration 5 : Avance des soldats bulgares sur le front.

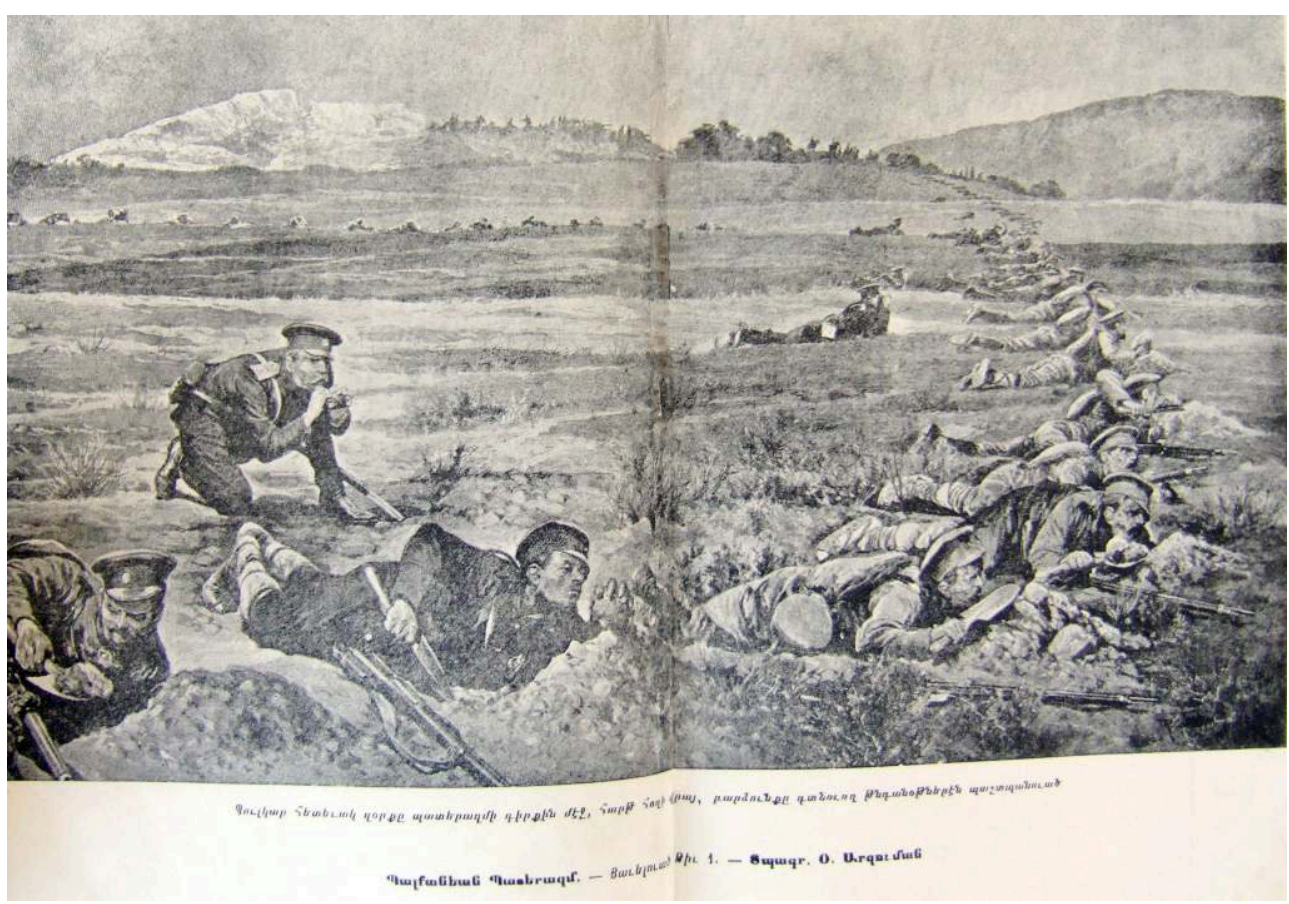

Tous les belligérants, sauf les Monténégrins, disposent d'avions. Avions et ballons servent à la reconnaissance de la cible ou du champ de bataille, tel le ballon bulgare Sofia lâché au-dessus d'Edirne. Mais les avions permettent déjà de bombarder l'ennemi : dans son habitacle un aviateur bulgare tient à la main une bombe à ailettes qu'il s'apprête à lâcher( p. 176). La guerre est aussi une guerre maritime. Les flottes grecques et turques ont joué un rôle décisif en pratiquant le blocus des côtes: des tableaux comparatifs des forces navales (p. 123), des schémas de bataille, des photos de cuirassés rappellent ce rôle.

Les images de la guerre balkanique révèlent l'implication croissante des civils durant les opérations militaires. Volontaires ou forcés, les déplacements de population font suite à l'occupation territoriale -en général une ville et ses abords- par telle ou telle armée ennemie. Durant la Première guerre balkanique, ce sont les Musulmans qui sont victimes des mesures incitatrices au départ comme le montre l'incendie par les Bulgares d'un village turc terrorisé (p. 320). C'est par centaines de milliers que ces mouhadjirs (réfugiés), chassés de leurs terres tentent de gagner les régions restées sous l'autorité du Sultan. A Sirkédji, les mouhadjirs de Roumélie quittent l'Europe dans une cohue indescriptible où se mêlent hommes, animaux et chariots (p. 35) ; à Salonique, hommes et femmes voilées paraissent accablés et résignés à leur sort (p. 814). Les images accablantes se succèdent : des vieillards et une nuée d'enfants "turcs" devant un camp de tentes (p. 837), des femmes voilées, réfugiées de Macédoine, au milieu de leur marmaille ( $p .849)$ etc. Ces images ont pour corollaires les images de la déroute humiliante de l'armée ottomane. Serbes dégageant les cadavres des soldats turcs des 
tranchées de Monastir, retraite désordonnée de l'armée turque (p.884-885), reddition et désarmement des Turcs à Janina (p. 932), longue file de prisonniers turcs ${ }^{41}$ sur une route sans fin (p. 588), prisonniers turcs aux mains des Hellènes( p. 860), à Janina ( $p$. 902), à Athènes (p. 929), monticule de fusils abandonnés par les Turcs à Monastir, artillerie légère turque abandonnée à Koumanovo (p. 713), à Sarandaboros (p. 835), à Salonique (p. 838), soldats de la Coalition peignant avec arrogance une croix sur les fez des prisonniers turcs (p. 829), soldats turcs cholériques isolés devant la mosquée Aya Sophia (p. 982).

Illustration 6 - les femmes monténégrines sur le champ de bataille

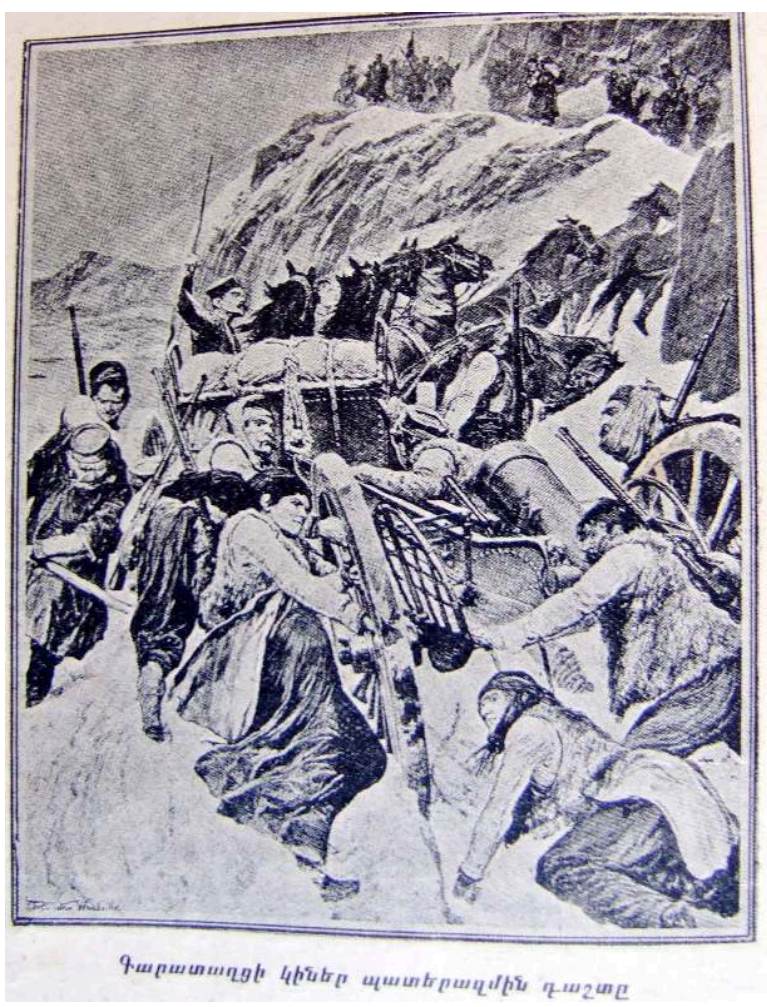

34 Ce que les photographies ne montrent pas, c'est l'ampleur des souffrances subies par les soldats et les civils y compris chez les vainqueurs, le sort des blessés, la carence des services de santé, la disette générale (toutes les armées vivent sur le pays) et la propagation des épidémies. Dans son texte, Andonian décrit les malheurs de la guerre et évoque souvent le coût humain élevé du conflit balkanique. Faute de donner des chiffres, il se contente de reproduire à la fin de chaque fascicule le même dessin satirique : la mort, sous la forme d'un squelette, aiguise sa faux sur une roue qu'elle active énergiquement de ses pieds décharnés...

Les images de l'Histoire de la guerre balkanique permettent de décrypter les caractères particuliers de cette guerre. L'embrigadement des peuples, l'usage de toutes les armes, les nouvelles techniques de combat, l'implication des populations civiles soumises à des épreuves terribles annoncent les formes de "guerre totale" de la Première guerre mondiale. 


\section{Un objectif : la relance de la Question arménienne (1912-1914)} et même l'intelligentsia arménienne révolutionnaire avec le gouvernement tsariste ${ }^{44}$. En effet, conséquence de la "réaction stolypinienne", le grand Procès du Dachnaktzoutioun qui se déroule à Saint-Pétersbourg s'est terminé par un verdict relativement clément (1912) ${ }^{45}$. Brusquement, au début du mois d'octobre 1912, tandis que la Turquie subit de sévères défaites militaires dans les Balkans, une conférence où sont représentés tous les courants politiques arméniens se tient à Tiflis avec l'aval des autorités russes et procède à l'élection d'un Bureau National (Azkayin Buro ) constitué de personnalités éminentes, depuis l'évêque Mesrob, le poète Hovannès Toumanian jusqu'à Alexandre Khatissian, le maire de Tiflis ${ }^{46}$. L'objectif de la conférence est de relancer le projet de réformes à accomplir en Arménie turque où la situation n'a cessé de se dégrader depuis la Révolution de 1908 (massacres d'Adana mars-avril 1909, insécurité permanente, violences kurdes, question agraire et exode rural dans les vilayet orientaux). Le Bureau qui a été béni par Kévork V l'engage à demander au tsar, au nom des Arméniens de Russie, d'accorder son soutien aux Arméniens de Turquie. Il 
règne alors chez les Arméniens du Caucase une effervescence patriotique et la conviction qu'il faut savoir profiter du "moment historique» pour réaliser ses «ambitions nationales » ${ }^{47}$. Cette attitude est approuvée par le prince Vorontsov-Dachkov. Dans la lettre personnelle qu'il adresse à Nicolas II, le 9 octobre 1912, il explique qu'il a découragé Kévork V d'entreprendre un voyage à Saint-Petersbourg, mais qu'il lui a proposé, avec l'accord préalable du Président du Conseil des Ministres, de transmettre au tsar une demande écrite. Demande qu'il appuie au nom des intérêts de la Russie en Asie Mineure, qu'il justifie par le cours des relations russo-turques depuis 1877-1878 et par "l'orientation russe" attestée des Arméniens".

Dès lors, assuré du soutien absolu du Vice-roi, fasciné par l'exemple de Meguerditch Khrimian ${ }^{49}$ en 1878, poussé par le Bureau national, Kévork V signe un kontak (novembre 1912) nommant Boghos Nubar Pacha à la tête d'une Délégation Nationale Arménienne ${ }^{50}$. Sa mission est de se rendre à Paris et de promouvoir la cause arménienne auprès des six Puissances signataires du traité de Berlin(1878). Quand, au début de décembre, Boghos Nubar Pacha arrive à Paris, la Turquie vient de demander un armistice (3 décembre 1912). Dans une lettre adressée le 19 décembre 1912, au Président du Conseil, Raymond Poincaré, Archak Tchobanian ${ }^{51}$, confirme cette nomination par « le chef de l'Eglise et de la Nation Arméniennes (...) avec le consentement du gouvernement russe qui comme vous le savez est actuellement très disposé à prendre en mains la question arménienne $"^{52}$. Quelques jours auparavant, le 10 décembre 1912, la revue parisienne Pro Armenia qui s'était sabordée en 1908 après la Révolution jeune-turque, vient de réapparaître sous un nouveau titre, Pour les Peuples d'Orient, ${ }^{53}$ confirmant ainsi la fin de la trêve politique entre la FRA et le CUP (Comité Union et Progrès). A partir de Paris, Boghos Nubar Pacha se livre à des déplacements incessants qui le mènent à Berlin, à Genève, à Londres ${ }^{54}$. Dans cette ville, ses contacts avec de hauts dignitaires anglais sont relayés par l'influent British Armenia Committee qui tente de faire inscrire les réformes en Arménie turque dans le calendrier de la Conférence de Londres réunie, sous l'égide des Puissances, pour la signature de la paix entre les Etats balkaniques et l'Empire ottoman( mai 1913)55.

Entre novembre 1912 et l'été 1913, à Saint-Pétersbourg, Tiflis, Paris et Constantinople, toutes les organisations arméniennes se mettent à collecter, publier et diffuser des documents et des statistiques qui doivent permettre d'appuyer les initiatives de la diplomatie russe en faveur des réformes. A Constantinople, véritable centre névralgique, le Patriarche arménien, Hovhannès Archarouni (1911-1913) submergé par les takrir (les suppliques) envoyés d'Anatolie, est en relation permanente avec Kévork V et avec de Giers, l'ambassadeur de Russie. Il lui faut aussi assurer des relations délicates avec le Sultan Mehmet V, avec le gouvernement ottoman et avec les Jeunes-Turcs détenteurs du pouvoir.

Le 21 décembre 1912, l'Assemblée Nationale Arménienne ${ }^{56}$ réunie à huis clos à Galata, crée une Commission de Sécurité qui doit coordonner les actions. Au cours de cette séance historique Gabriel Noradounghian, ministre des Affaires étrangères de l'Empire ottoman, exprime son opposition à une politique d'intervention. Le patriarche Archarouni, âgé et timoré, est poussé à démissionner (août 1913). Il est remplacé en octobre par l'archevêque Zaven Ter Yéghiayan, un jeune prélat dont la carrière s'est déroulée à Erzeroum, Van et Diarbékir, qui connaît les problèmes des vilayet orientaux, et se montre capable de collaborer avec les acteurs arméniens (hommes d'Eglise, intellectuels, militants politiques, journalistes) à la mise en oeuvre des réformes. 
Une fois encore, l'enjeu du nombre est au centre du conflit qui s'engage entre Arméniens et Turcs: les Arméniens sont-ils majoritaires dans les vilayet orientaux susceptibles de bénéficier d'une réforme administrative spécifique ? Ainsi, le Patriarcat de Constantinople lance une véritable enquête qui aboutit à la publication des fameuses Statistiques du Patriarcat arménien (1912-1913) ${ }^{57}$. Ainsi, Krikor Zohrab publie à Paris, sous le nom de Marcel Léart, La Question Arménienne à la Lumière des Documents (1913) un petit ouvrage assorti d'une étude démographique et économique sur le vilayet de Sivas.

Le livre publié, entre les deux révolutions russes de 1917, par André Mandelstam, (1878-1949), spécialiste de droit international et ancien drogman de l'ambassade de Russie à Constantinople, Le sort de l'Empire ottoman, donne un éclairage précis sur les objectifs de la diplomatie russe en Turquie d'Asie au cours des guerres balkaniques ${ }^{58}$. Publié deux ans après les mesures édictées par les Jeunes Turcs qui ont conduit au génocide des Arméniens de l'Empire ottoman, l'ouvrage est un plaidoyer pro domo justifiant la politique d'intervention de la Russie de 1912 à 1914 en faveur de ces mêmes Arméniens.

"Ce livre est la meilleure réfutation des accusations perfides portées par la Porte contre la Russie et les Arméniens pour expliquer ou justifier les horribles massacres de 1915. Le gouvernement impérial russe ne songe pas à cacher que les sympathies des malheureuses masses arméniennes pendant l'époque qui précéda les massacres allaient à la Russie, de laquelle elles attendaient salut et protection sous n'importe quelle forme. Mais il établit en même temps de manière irréfutable que ni lui, ni le patriarcat ou les chefs autorisés du peuple arménien ne visaient à autre chose qu'à des réformes contrôlées par les Puissances. Ce n'est qu'en cas d'échec de ces réformes que le gouvernement russe aurait envisagé l'occupation de ce foyer de troubles et de désordres, qui menaçait la sécurité de ses propres provinces" ${ }^{59}$.

Le 30 novembre (1912), Sazonow le ministre russe des Affaires étrangères, dans une lettre adressée à l'ambassadeur de Giers, le charge d'attirer l'attention de la Porte sur le fait que « la question arménienne, à moins de réformes introduites à temps, pourrait amener une intervention européenne». Toutefois, il ne souhaite pas une internationalisation immédiate de la question arménienne : la crise balkanique n'étant pas terminée, on peut craindre des dissentiments entre les Puissances ${ }^{60}$. Mais la Russie veut se réserver l'initiative des opérations. Début décembre 1912, alors que la Turquie a demandé et obtenu un armistice (3 décembre 1912), de Giers reçoit le Dr. Zavriev ${ }^{61}$ pour lui annoncer que le gouvernement russe s'intéresse au sort de l'Arménie et en même temps mettre en garde les Arméniens contre toute action imprudente. "Il importe qu'aux yeux de l'Europe, les Arméniens restent les victimes de l'arbitraire turc et ne se transforment pas en révolutionnaires politiques désireux de profiter des échecs militaires turcs pour la réalisation de leurs aspirations nationales». En revanche, "ils ont le droit, dans la presse et dans leurs manifestes, d'attirer l'attention générale sur les abus révoltants dont ils sont victimes de la part des Kurdes et des autorités turques ${ }^{62}$.

La réaction du gouvernement ottoman dirigé par le libéral Ahmed Muhtar pacha dont le ministre des Affaires étrangères est l'Arménien Gabriel effendi Noradounghian ${ }^{63}$ est d'éviter une réforme spéciale pour l'Arménie et de proclamer des réformes générales pour tout l'empire sous la forme d'une nouvelle loi sur l'administration des vilayet introduisant le principe de la décentralisation administrative. Sans entrer dans les détails, la joute diplomatique s'engage entre la Russie, à peine approuvée par la France et la Grande-Bretagne ses partenaires de la Triple Entente, et le gouvernement ottoman dont la résistance est soutenue par les Etats de la Triplice, mais surtout par l'Allemagne 
dont le secrétaire d'Etat aux Affaires étrangères, von Jagow, est particulièrement hostile au projet russe.

Présenté à la Conférence des Ambassadeurs des six Puissances, réunie le 17 (30) juin 1913 à Constantinople, l'Avant-projet des réformes à introduire en Arménie a été rédigé par André Mandelstam ${ }^{64}$ d'après les indications données par l'ambassadeur de Giers et conformément aux instructions envoyées de Saint-Petersbourg par Sazonow ${ }^{65}$. Il est rejeté par le gouvernement Jeune-Turc qui propose à la hâte un nouveau projet de réformes générales pour l'empire. L'action diplomatique fermement menée par la Russie triomphe de l'opposition austro-allemande et obtient l'accord de l'Allemagne sur le projet final. Avant de signer l'accord russo-turc du 26 janvier (8 février)1914 sur les réformes en Arménie turque, le gouvernement ottoman résiste jusqu'au bout.

À la place des six vilayet orientaux (Erzeroum, Bitlis, Van, Sivas, Kharpet, Diarbékir) auxquels a été ajouté le vilayet de Trébizonde, sont créées deux provinces anatoliennes placées sous la direction de deux inspecteurs européens chargés d'accomplir, avec la collaboration des populations locales, les réformes indispensables. La nomination des inspecteurs, le hollandais Westenenk et le norvégien Hoff a lieu en avril 1914. Le conflit mondial commencé en Europe le 2 août 1914 et la décision des Unionistes d'entrer en guerre aux côtés de l'Allemagne, le 29 octobre (11 novembre)1914 offrirent à la Turquie "l'occasion d'une revanche historique sur la Russie $»^{66}$. Et aussi l'occasion de mettre un terme définitif à la question arménienne.

Nous ignorons comment la maison d'édition Arzouman a pris la décision de publier la chronique de la guerre balkanique et d'en confier la direction à Aram Andonian. Comment l'entreprise a-t-elle été financée? Quels ont été les tirages et le mode de diffusion des fascicules? Quelle a été la réception du public ? Pourquoi la publication at-elle cessé à l'été 1913 ? Echec financier ou pression politique des Jeunes-Turcs arrivés au pouvoir?

Le livre s'inscrit dans la série des actions engagées, de 1912 à 1913, par les organisations religieuses et civiles arméniennes dans la bataille des réformes pour l'Arménie turque. Journaliste brillant, intuitif et révolté, à la recherche du succès, Aram Andonian a peutêtre bénéficié des conseils et de la protection de Krikor Zohrab. Comme ce dernier, il est sensible au "modèle bulgare" et reste convaincu que la conjoncture politique est favorable à la solution de la question arménienne. Une idée qu'il défendra dans le journal satirique Kiko jusqu'aux premiers jours de la Première guerre mondiale.

Paris (novembre 2006-janvier 2007)

\section{ANNEXES}




\section{Préface}

Peu de guerres ont apporté d'un seul coup autant d'émotions, d'inquiétudes et d'intérêts, peu de guerres ont eu une portée politique aussi importante que l'actuelle Guerre Balkanique.

La coalition de quatre petits et jeunes États dressés contre l'Empire ottoman dont ils étaient hier encore les provinces, les succès ahurissants qui ont couronné leur audace et leur initiative, ouvrent une nouvelle page de l'histoire de la Question d'Orient, question réputée compliquée et insoluble, mais qui semble désormais promise à une solution finale.

Si l'on sait que depuis presque quatre siècles la diplomatie européenne, au prix de conflits terribles et de sacrifices innombrables, a en vain cherché à obtenir ce résultat, si l'on réalise la rapidité inattendue et presque foudroyante avec laquelle ce résultat a été obtenu, c'est alors que l'on comprendra le sens de cette guerre qui a surpris les spécialistes les plus avertis et stupéfié le monde entier.

Outre ce résultat inattendu, la guerre actuelle a des côtés étonnants tous dignes d'attention et surtout de réflexion. Le premier point digne d'attention c'est d'abord la coalition elle-même des quatre États balkaniques. Hier encore ces quatre Etats étaient ennemis. La Bulgarie et la Serbie avaient, dès leur indépendance, lutté l'une contre l'autre et, ces dernières années, les Serbes ne semblaient pas avoir oublié leur défaite. Il y a encore quelques années, Grecs et Bulgares se massacraient mutuellement. Les Monténégrins et les Serbes, malgré leur consanguinité, s'agaçaient continuellement et s'entretuaient eux aussi. Comment s'est réalisée l'union de ces Etats ennemis autour d'un seul objectif? Comment surtout ont-ils pu s'entendre sur cet objectif qui était jusqu'ici leur vraie pomme de discorde? Comment ont-ils pu construire un idéal national à partir d'une cause haineuse? Comment ont-ils réussi à endormir leur vieille inimitié et réaliser, rassemblés et unis, cet idéal si magnifiquement.

L'autre élément digne d'attention, c'est l'affaiblissement et la défaite de la Turquie qui ont stupéfié le monde autant que les succès des petits Etats. Il n'y a pas de doute que la Turquie avait de nombreuses justifications. Parmi elles, les conditions accablantes dues à un quart de siècle de despotisme freinant et rendant impossible le développement des forces politiques, intellectuelles, économiques et surtout militaires du pays. Ont suivi ensuite, sous le couvert de la Constitution, cinq années de gouvernement des Jeunes-Turcs dont la faiblesse, l'imprévoyance et les erreurs ont été aussi néfastes pour le progrès et la consolidation du pays que le despotisme qu'il avait renversé. Sa part de responsabilité a même été plus grande dans la mesure où il n'a pas manqué de conseillers sincères et désintéressés qui, prévoyant la chute, n'ont cessé de le mettre en garde contre cet avenir terrible. Resté toujours sourd, il a préféré aux conseils sensés sa propre sottise. Pour les gouvernants actuels de la Turquie, tout ceci suffit à expliquer la situation Et encore, il est incontestable que l'armée turque, malgré une série de défaites, s'est montrée réellement capable d'héroïsme dans les situations les plus difficiles et les plus désespérées. Mais la politique n'est pas une question de sentiment. On juge la guerre par son résultat et ce résultat aujourd'hui est totalement défavorable à la Turquie. A la table des négociations de paix nul ne se souciera de savoir pourquoi tel ou tel camp a été vaincu Désormais une seule question domine les esprits. Quelle va être la conséquence de la défaite? Quel sera le prix payé par le vaincu? Que lui restera-t-il?

Les lecteurs trouveront des réponses à ces questions alarmantes dans cet ouvrage à la fois général et détaillé que nous élaborons en nous fondant, sans parti pris, sur les sources les plus fiables et les plus objectives, uniquement poussés par la recherche de la vérité, fut-elle l'amère vérité. Au cours de ce travail nous aurons l'occasion de montrer les conséquences politiques de la 
guerre actuelle et des nouvelles crises internationales et de considérer quel ordre politique s'imposera en Turquie.

Pour nous autres Arméniens ce travail aura aussi son côté intéressant car les événements actuels jouent un peu avec le destin du peuple arménien. Bien entendu, à l'heure où nous écrivons ces lignes l'avenir nous est inconnu, mais il n'y a pas de doute que les changements qui interviendront dans le déplorable système établi depuis si longtemps, apporteront leur part de bénéfices à notre malheureux peuple. Quel que soit l'avenir de la Turquie, ses dirigeants tenteront, sans aucun doute, de tirer profit des tristes leçons du présent en créant, partout dans le pays et pour toutes les races sans exception, des conditions d'existence réellement supportables.

En considérant tous ces aspects intéressants, ce travail va aboutir au meilleur livre de notre temps et rencontrer de la part du public un large accueil qui, nous l'espérons ne nous sera pas refusé. De notre côté, nous allons tout mettre en oeuvre pour le rendre plus utile et plus attrayant et allons porter un soin particulier à son illustration. A cette fin, nous sommes déjà entrés en contact avec des éditeurs célèbres d'Europe et d'Amérique : les "clichés" qu'ils vont nous envoyer seront publiés, au fur et à mesure, dans les chapitres suivants.

A la lumière du passé il est possible de comprendre le présent. Les événements qui se succèdent aujourd'hui à la vitesse de l'éclair et qui nous stupéfient par les transformations politiques qu'ils induisent, nous paraîtront tout à fait naturels, si nous nous souvenons d'un certain nombre d'événements significatifs du passé récent. Ils sont à l'origine de la guerre actuelle. Comme aujourd'hui, ils provoquèrent, il y a un quart de siècle, une grave crise en Orient. Mais ses conséquences ne furent pas aussi décisives que promettent de l'être celles d'aujourd'hui.

Pour rester fidèle à notre programme, avant de passer à l'examen rigoureux des actions militaires, nous allons survoler ce passé récent afin que les lecteurs puissent aisément trouver, comprendre et pénétrer en profondeur les causes exactes des événements actuels.

Cette guerre a commencé il y a un mois et déjà tous les calculs des diplomates ont été bouleversés, toutes les promesses du "Statu quo" ont été détruites, la carte de l'Europe a été profondément modifiée et l'équilibre européen a été en quelque sorte chamboulé. Et tout ceci a eu lieu "sans l'intervention des Grandes Puissances" comme le faisait remarquer un journal français, le 21 novembre.

Comment ce miracle s'est-il-produit? Cet ouvrage va l'expliquer de manière scrupuleuse et détaillée.

Aram Andonian (traduit de l'arménien par Anahide Te Minassian)

\section{NOTES}

1. Le terme arménien accolé au nom d'Aram Andonian kazmétz signifie " a donné forme ", "a réalisé ».

2. De 1901 à 1902, puis de 1906 à 1908, il est rédacteur ou membre du comité de rédaction d'une des meilleures revues arméniennes de Constantinople Tzarik (Fleur, 1886-1911) maintes fois interdite par la censure. Il est rédacteur durant quelques mois en 1908, de la revue littéraire Louys (Lumière, 1895-1908). Au lendemain de la révolution, il lance en 1908 un hebdomadaire satirique Hokkabaz qui, édité en arménien, français, grec et turc, n'a pas dépassé le troisième numéro. Une nouvelle revue "satirique et politique " Kharazan (Fouet, 1909) dont il est le rédacteur et à laquelle collabore Yervant Odian, disparaît après le neuvième numéro pour être remplacée 
par un hebdomadaire illustré Karapnad (Guillotine) qui réussit à durer une année (1909-1910). Mais si, pour des raisons financières ou policières, il n'a pu avoir son propre périodique, Aram Andonian a collaboré au quotidien Sourhantak (Messager, 1899-1908) et surtout à Kiko (1909-1914), un excellent journal satirique rival du célèbre Gavroche. Aram Andonian a eu aussi des projets pédagogiques et des ambitions littéraires. A côté de recueils de textes destinés aux élèves arméniens, il a publié des études sur des écrivains arméniens : Missak Métzarentz (1907), Chirvanzadé (1911). Un roman paru en feuilleton dans Sourhantak (à partir du n¹531, en 1904) "Sous le voile de l'argent » est resté inachevé ; une nouvelle, "La vérité”( 1909). Dans la série, Statues de plâtre, il publie (1910) une satire dont la férocité du texte est accentuée par la cruauté des dessins contre Haroutioun Chahrikian (1860-1915) représentant à ses yeux l'espèce haïe des militants dachnak caucasiens surgis à Constantinople après la révolution de 1908. Dans la même série, il prendra aussi pour cible le hintchak Haroutioun Djangulian rentré, quant à lui, des EtatsUnis.

3. Bibliothèque constituée par le fonds légué à l'Union Générale de Bienfaisance par Boghos Nubar pacha (1851-1930), président de la Délégation Nationale Arménienne de 1912 à 1921.

4. Hagop Der Hagopian, «Aram Andonian » (en arménien), Haratch, 30 décembre, 1951 et 1er janvier 1952.

5. Bolis désigne en arménien Constantinople.

6. Assemblée élue de l'Ermeni Millet dans le cadre de la « Constitution Nationale » de 1863.

7. C'est le Amenoun daretzouitz (Almanach de tous), publié à Constantinople de 1907 à 1915 et en 1920, à Venise de 1921 à 1926, à Paris de 1927 à 1928. L'autobiographie d'Aram Andonian est dans le numéro de 1913, pp. 364-367.

8. Hrand Assadour (1862-1928); Krikor Zohrab (1861-1915), avocat, journaliste, écrivain, député au Parlement ottoman a été l'Arménien le plus célèbre de son temps avant d'être déporté et exécuté en 1915.

9. Publié de 1884 à 1912. A changé plusieurs reprises de directeur et d'orientation.

10. Ainsi, Andonian a été l'opposant farouche du patriarche Ormanian (1896-1908) et le partisan résolu d'un personnage douteux, Ghevond vartabed du monastère de Jérusalem.

11. Parti issu de l'éclatement du parti social-démocrate hintchakian, fondé à Genève par des étudiants caucasiens (1887), après les massacres hamidiens de 1894-1896. Petit parti animé par des militants arméniens de l'Empire ottoman a abandonné le programme socialiste et révolutionnaire primitif, mais a conservé une sensibilité populiste.

12. Fondé à Tiflis en 1890, par des Arméniens du Caucase. Parti révolutionnaire dont l'objectif est l'émancipation des Arméniens de Turquie, membre de la Seconde Internationale depuis 1907.

13. En 1911, Aram Andonian édite La vie comme elle est de Zohrab

14. Fervent défenseur de la liberté de la presse, Aram Andonian s'est acquis la reconnaissance de la postérité grâce à un célèbre dessin publié dans Hokkabaz (13/09/1908, cf.supra n.4). Un général turc pointe son revolver sur un supplicié décharné lié à un poteau que surmontent deux calames entrecroisés et un carton où le mot « presse » est écrit en caractères arabes, arméniens, français et grec. Dessin reproduit in Bozarslan (Hamid), Les Courants de pensée dans l'empire ottoman, 1908-1918, thèse soutenue sous la direction de François Furet, EHESS, Paris, 1992, p. 463.

15. Kévonian (Dzovinar), Réfugiés et Diplomatie humanitaire, Les acteurs européens et la scène procheorientale pendant l'entre-deux guerres, Paris, Publications de la Sorbonne, 2004.

16. La querelle porte sur l'authenticité des télégrammes. Ternon (Yves), Enquête sur la négation d'un génocide, Marseille, Parenthèses, 1989, pp.77-124. Un jeune historien turc, Fuat Dûndar, dans son intervention au séminaire de François Georgeon, à l'EHESS, le 6 avril 2006, intitulé « Recenser et cartographier les populations de l'empire ottoman » a rejeté les documents Naïm-Andonian, mais dévoilé les cartes ethnographiques et les recensements des populations anatoliennes établis par les Jeunes-Turcs avant et durant la Première guerre mondiale (trouvés dans les archives 
ottomanes à Istanbul) et démontré l'existence d'une politique régionale d'épuration ethnique aux dépens des Arméniens, des Grecs, des Kurdes, des Assyro-Chaldéens.

17. Kévorkian (Raymond), Le génocide arménien, Paris, Odile Jacob, 2006.

18. L'Autriche-Hongrie (annexion de la Bosnie, appui apporté à la création d'un Etat albanais) semble contrarier plus que l'Empire ottoman la politique slavophile de la Russie.

19. Hall (Richard C.), The Balkan Wars 1912-1913, Prelude to the First World War, New York, Routledge, 2000; Mazower (Mark), The Balkans, a short history, New York, Modern Library Editions, 2000; Weibel (Ernest), Histoire et géopolitique des Balkans de 1800 à nos jours, Paris, Ellipses, 2002; Ternon (Yves), Empire ottoman, le déclin, la chute, l'effacement, Paris, Ed. Le félin, 2002; Cosson (Olivier), Horizons d'attente et expériences d'observations au début du XXe siècle. Les militaires français face aux conflits périphériques (Afrique du Sud, Mandchourie, Balkans), Paris, EHESS, 2006, une thèse passionnante.

20. Bartlet, correspondant du Daily Telegraph, cité par le Lieutenant-Colonel Boucabeille, $L a$ guerre turco-balkanique,1912. Thrace, Macédoine, Albanie, Epire, Paris ,Chapelot 1913, p. 168.

21. Idem, p. 182. Il s'agit de Ferdinand de Saxe-Cobourg

22. Carnegie Endowment for International Peace, Report of The International Commission to Inquire into the Causes and Conduct of the Balkan Wars, Washington, 1914.

23. Une carte (en caractères arméniens) du livre d'Andonian (p. 389) donne des chiffres plus élevés qui font état de l'appel des réservistes. Elle établit la démographie et les ressources financières des Etats en guerre. Elle attribue à la Turquie la capacité de mobiliser 1400000 hommes. Voir infra note 31.

24. Trotsky (Lev), Les guerres balkaniques 1912-1913, Paris, éd. Science Marxiste, 2002, traduction française de l'édition russe Moscou-Léningrad, 1926. Un recueil d'articles publiés dans la presse russe( Pravda, Kievskaja Mysl', Den', Luc) de 1910 à 1913 par celui qui n'est encore qu'un militant marxiste et déjà un écrivain hors du commun.

25. Il les donne p. 910.

26. Photos des correspondants civils et militaires étrangers sur le front bulgare p. 305.

27. En conclusion de sa thèse Olivier Cosson constate que chez les militaires français "L'organisation inlassable d'offensives meurtrières figure de manière très nette au programme de commandement dans les années avant 1914 (...)Les guerres périphériques ont placé les cadres de l'armée face à des expériences de guerre porteuses d'une violence nouvelle qui les ont familiarisés de manière déterminante aux sacrifices de masse exigées par la guerre moderne", op. cité, p. 612.

28. Andonian utilise toujours le nom turc de Karadagh.

29. Voir en annexe notre traduction de la préface, infra pp.26-28.

30. Ramené de son exil salonicien à Constantinople, Abdulhamid II ne cesse de se lamenter "Comment est-il possible que la Grèce se soit alliée à la Bulgarie? Nos dirigeants n'ont-ils pu prévenir cette alliance? ", cité dans Georgeon (François), Abduhamid II, le sultan calife, Paris, Fayard, 2003, p. 436.

31. Driault (Edouard), La Question d'Orient, Préface de Gabriel Monod, Paris, Félix Alcan, 1910, 4e édition; Pinon (René), L'Europe et l'empire ottoman, Les aspects actuels de la Question d'Orient, Paris, Perrin, 1909; Bérard (Victor), La mort de Stamboul. Considérations sur le gouvernement des JeunesTurcs, Paris, Colin, 1913.

32. Andonian (Aram), op. cit., p. 204.

33. $Y$ compris Les armées des principales puissances au printemps 1912, Paris, Chapelot, 1912.

34. Pennenrun (Alain de), Breveté d'Etat-Major, La guerre des Balkans. Campagne de Thrace, Paris, Charles Lavauzelle, 1913.

35. Lieutenant-colonel breveté Boucabeille, La guerre turco-balkanique, 1912, Thrace-MacédoineAlbanie-Epire, Paris Chapelot, janvier 1913, 3e édition, 226 p.

36. Idem, p. 5. La remarque de Boucabeille est justifiée par les périodiques français qu'il cite (Presse française, Le Temps, Le Matin, Les Débats, L'Illustration, le Journal, l'Echo de Paris etc.) et leurs 
correspondants qui s'appellent Pennenrun, Naudeau, Bartlet, Puaux, Rémond, de Segonzac, Vallier, Rhodes, Erio, Geffryer etc.

37. Les autres livres cités par Andonian sont les suivants. Pennenrun (Alain de), Feuilles de route bulgares. Journal de marche d'un correpondant de guerre pendant la campagne de Thrace, Paris, Chapelot, 1913; Lieutenant H. Wagner de l'Armée austro-hongroise, correspondant de guerre de la Reichspost, Vers la victoire avec les armées bulgares, Paris, Berger-Levrault, 1913; Lauzanne (Stéphane), correspondant du Matin, Au chevet de la Turquie. Quarante jours de guerre, Paris, A. Fayard, 1913; Puaux (René), correspondant du Temps, De Sofia à Tchataldja, Paris, Perrin \& Cie, 1913; Hochwächter (Major Gustav von), attaché à L'Etat-Major de Mahmoud Mouktar Pacha, Au feu avec les Turcs. Journal d'opérations ( Kirkkilissé, Lulé Bourgas, Tchataltcha), Paris, Berger-Levrault, 1913; Loyseau de Grandmaison (Capitaine L.), La guerre des Balkans. Esquisse générale des opérations, Paris, Berger-Levrault, 1913.

38. Elle est constamment rappelée par les allusions aux réformes promises dans l'article 23 (pour la Macédoine) et dans l'article 61 (pour l'Arménie) du traité de Berlin et à l'indifférence de l'Europe qui a laissé s'accomplir les massacres hamidiens, en dépit du memorandum de 1895. On retrouve cette même comparaison sous la plume de Trotsky, op. cité, pp. 250- 267. C'est un exposé remarquable des questions macédonienne et arménienne publiée dans Kievskaja Mysl', n 197, le 19 juillet 1913. Posté à Sofia, Trotsky vient de rencontrer Andranik (1865-1927), le plus célèbre des fédaïs arméniens, entouré d'une troupe de 250 volontaires arméniens engagés aux côtés des Bulgares et contre les Turcs. Une rencontre étonnante et l'occasion pour Trotsky de faire une analyse pertinente du mouvement révolutionnaire arménien et de la révolution jeuneturque.

39. Assassinat du roi Georges de Grèce représenté p. 896.

40. Surtout de l'artillerie lourde, artillerie de forteresse capable d'arrêter les assaillants comme à Tchataltcha.

41. Les images de prisonniers sont relativement rares. Au cours de la Première guerre faute de pouvoir assurer le ravitaillement des armées on fait peu de prisonniers. Durant la Seconde guerre, ce comportement est général et traduit la « barbarisation » du conflit.

42. La question arménienne a été internationalisée au Congrès de Berlin (1878). L'article $61 \mathrm{du}$ traité de Berlin faisait obligation au sultan de faire des réformes dans les provinces "habitées par les Arméniens"et soumet leur application au contrôle des Puissances. Elles ne furent jamais appliquées. Les massacres arméniens de 1894-1896 n'entraînèrent aucune intervention des Puissances, à l'exception d'un mémorandum (Angleterre, France, Russie) présenté au sultan en 1895.

43. Souligné dans le texte. Il s'agit des conséquences de la Deuxième guerre balkanique (voir supra p.8) : la défaite de la Bulgarie, le renforcement de la Serbie, et le redressement militaire inattendu de la Turquie.

44. Ter Minassian (Anahide), «La révolution russe de 1905 en Transcaucasie, » in Coquin (F.-X. ) et Gervais-Francelle (Céline) (dir.), 1905 : La Première Révolution russe, , Paris, Publications de la Sorbonne, 1986, pp. 315-334.

45. Le Dachnaktzoutioun ou Fédération révolutionnaire arménienne (F.R.A.) est accusé d'avoir voulu renverser le gouvernement tsariste par une série d'actes terroristes entre 1903 (confiscation des Biens du clergé arménien par le gouvernement russe) et 1907, dont l'acmé se situe durant la "guerre arméno-tatare". Les accusés sont 160, le dossier d'accusation comprend 20000 pages, les avocats de la défense s'appellent Kerenski, Milioukov, Grusenberg, Zaroutni.

46. Alexandre Khatissian (1876-1945), Premier ministre de la République d'Arménie indépendante en 1919.

47. Vratsian (Simon), Kianki oughinérov (Sur les chemins de la vie), Beyrouth, 1963, t. 3, pp. 38-44.

48. "Pisma I.I. Vorontsova-Dashkova Nikolaju Romanovu, 1905-1915”(“Lettres de I.I. VorontsovDachkov à Nicolas Romanov, 1905-1915), Krasnyi Arkhiv, 1928, XXVI, pp. 118-120. 
49. Meguerditch Khrimian (1820-1907), né à Van, patriarche arménien de Constantinople (1869-1873), catholicos à Etchmiadzine (1893-1907). A dirigé la petite délégation qui s'est rendue à Berlin, en 1878, pour plaider la cause arménienne.

50. Boghos Nubar Pacha (1851-1930), fils d'un pacha arménien réformateur d'Egypte.

51. Archak Tchobanian (1872-1954), poète, publiciste, exilé en France depuis 1893 membre de la Délégation Nationale arménienne. Très actif dans les milieux arménophiles français.

52. AMAE, Turquie NS XVI (nov. 1912-avril-1913), fol. 80-81.

53. Pro Armenia, organe de propagande du parti dachnak publié en fançais et à Paris de 1900 à 1908. C'est une création de Christapor Mikaélian, l'un des trois fondateurs du Dachnaktzoutioun. C'est le fruit d'une collaboration avec les démocrates et les socialistes français, G.Clemenceau, A.France, J.Jaurès, Fr.de Pressensé, E. de Roberty. Le secrétaire de rédaction est Jean Longuet. Le rédacteur en chef, Pierre Quillard, Vice-président, puis Secrétaire général de la Ligue des Droits de l'Homme jusqu'à sa mort (1912). Victor Bérard lui succède à la rédaction de Pour les Peuples d'Orient.

54. Pour suivre les déplacements et les entrevues de Boghos Nubar Pacha on peut consulter Kévorkian (Raymond), Le Génocide des Arméniens, Paris, Odile Jacob, 2006, pp. 179-211. Parmi les sources citées par l'auteur, les plus intéressantes sont les archives de la Délégation Nationale et les archives du Patriarcat conservées dans la Bibliothèque Nubar à Paris.

55. Nassybian (Akabi), Britanian yèv haygagan hartze (La Grande Bretagne et la Question arménienne), Beyrouth, 1994.

56. Voir supra n. 8.

57. Selon les statistiques du patriarcat, il y avait en 1882, 2660000 Arméniens dans l'Empire ottoman dont 1630000 dans les six vilayet orientaux. En 1912, conséquences des massacres de 1894-1896, des famines et de l'émigration, ces chiffres sont tombés à 2100000 et 1018000 . Ces chiffres sont contestés par les autorités turques qui admettent 1080000 Arméniens en 1882 et 1 170000 en 1914. Par ailleurs, il est exact que l'arrivée massive des mouhadjirs originaires du Caucase, de Crimée et des Balkans entraîne une islamisation progressive de l'Anatolie.

58. Mandelstam (André), Le sort de l'Empire ottoman, Lausanne, Paris, Payot, 1917, 630 p., pp. 206-245. Le ton général de cet ouvrage, publié durant la Première Guerre mondiale, alors que l'armée russe occupe encore le Plateau arménien, est anti-turc et anti-allemand. Théoricien du droit de "l'intervention comme sanction du droit international et du droit humain", Mandelstam fustige les gouvernements turcs pour leur politique de massacres et établit sur les massacres arméniens de 1915 un dossier, appuyé sur le Livre orange russe (1916).

59. op. cit., pp. 206-207.

60. Sur l'ensemble de la question, on peut se reporter au tome I du recueil de documents (en russe), The Genocide of Armenians, The responsability of Turkey and the Obligations of the World Community, Yuri Barsegov, Compiler, Editor, Author of the Forward and Commentary, Moscow, 2002, 3 vol. La principale source du premier volume est Reformi i Armenii, 26/11/ 1912- 10/05/1914, Petrograd, 1915.

61. Dr.Zavriev, Hagop Zavrian, (?-1920), Arménien de Russie, diplômé de l'Ecole de médecine militaire de Saint-Pétersbourg, membre du Dachnaktzoutioun, a exercé la médecine à Mouch dans le vilayet de Bitlis. Jouera un rôle politique important de 1915 à 1920.

62. Idem, p. 209.

63. Gabriel Noradounghian (1852-1936), né à Scütari, mort à Paris. Rejeton d'une famille d'amira, Il fréquente après une école primaire arménienne de Scütari, une école française à Kadigügh. De 1870 à 1875, il poursuit des études supérieures à Paris à l'Ecole des Sciences Politiques. A publié en quatre volumes un Recueil d'Actes Internationaux de l'Empire ottoman, Paris, Leipzig, Neuchâtel, 1897-1903. Après la Révolution de 1908, il est membre du Sénat ottoman, puis Ministre des Travaux Publics et enfin Ministre des Affaires Etrangères de 1912 à 1913. Il est en Suisse au début de l'année 1918. En novembre 1918, il est membre de la Délégation Nationale Arménienne à Paris. 
Il en assure la présidence à la place de Boghos Noubar Pacha lorsque celui-ci démissionne (juin 1921). Il assiste, dans les coulisses de la conférence de Lausanne (juillet 1923), à l'enterrement de la question arménienne. Meurt à Paris en 1936.

64. André Mandelstam est l'ami de Krikor Zohrab (cf. supra note 10). Il a été l'intermédiaire entre Krikor Zohrab et les ambassadeurs successifs de Russie de Giers et Goulkevitch dans la bataille des réformes. Ceci est confirmé par le Journal (Orakroutiounnèr) de K. Zohrab. Cf.Albert Charourian (éd.), Krikor Zohrab, Yérkèr (Oeuvres), Erevan, 2004, t. IV. K. Zohrab, député du Parlement ottoman, est arrêté, déporté et exécuté près d'Ourfa en juillet 1915, avec son ami le député dachnak d'Erzeroum, Vartkès Sérengulian. Des années après, Aram Andonian constituera à Paris un dossier sur la disparition des deux députés.

65. En XXII articles; il se base sur le mémorandum de 1895.

66. Bozarslan (Hamit), Histoire de la Turquie contemporaine, Paris, La Découverte, 2004, p. 19.

\section{RÉSUMÉS}

Cet article étudie le parcours d'Aram Andonian, journaliste arménien né à Constantinople et plus particulièrement son Histoire illustrée des guerres balkaniques parue en 1913. S'y trouvent analysés non seulement les opérations militaires de 1912-1913, mais également l'arrière-plan historique de la question d'Orient de 1878 à 1908, tout comme l'utilisation de la photographie dans la construction de l'ouvrage. En outre, ces évènements sont étudiés dans une perspective arménienne.

\section{INDEX}

Index géographique : Arménie, Balkans

Mots-clés : question arménienne, guerres balkaniques 